\begin{tabular}{|c|l|}
\hline Title & Dual dynamic chirality generated in the assembly of three achiral rods through the three fold twisting of a macrocycle \\
\hline Author(s) & Katoono, Ryo; Sakamoto, Kazuki; Suzuki, Takanori \\
\hline Citation & $\begin{array}{l}\text { Chemical communications, 55(38), 5503-5506 } \\
\text { https://doi.org/10.1039/c9cc02226k }\end{array}$ \\
\hline Issue Date & 2019-05-11 \\
\hline Doc URL & http://hdl.handle.net/2115/77880 \\
\hline Type & article (author version) \\
\hline File Information & revised_manu_CC-COM-03-2019-002226R2.pdf \\
\hline
\end{tabular}

Instructions for use 


\title{
COMMUNICATION
}

Received 00th January 20xx, Accepted 00th January 20xx

\section{Dual dynamic chirality generated in the assembly of three achiral rods through the three-fold twisting of a macrocycle}

\author{
Ryo Katoono, ${ }^{* a}$ Kazuki Sakamoto ${ }^{a}$ and Takanori Suzuki ${ }^{a}$
}

DOI: $10.1039 / \times 0 \times x 00000 x$

We demonstrated dynamic chirality based on assemblies of three achiral rods with a twisted macrocycle. The three-fold twisting of a macrocycle can lead to two different chiral forms with $C_{2^{-}}$or $D_{3^{-}}$ symmetry. Through a transmission of chirality to each dynamic chiral form, a helical-sense preference was successfully induced.

The assembly of achiral rods is a promising method for creating chirality. Especially, assemblies of three or more rods are interesting due to their diversity (Scheme 1-I). Chirality can be generated when two achiral rods are assembled. The arrangement of the third rod characterizes each chiral motif. In one case, three rods are helically stacked one above the other, which is a chiral motif that has often been used in supramolecular chemistry. ${ }^{1}$ Alternatively, the third rod can be arranged to form a cyclic architecture. Similar chiral motifs can be envisioned in a macrocyclic framework (Scheme 1-II); i.e., two rods are linked by a spacer unit at each terminal of the entirety of rods, resulting in a twisted macrocycle. A chiral arrangement with $C_{2}$-symmetry is generated by "heterochiral" twisting, where the macrocycle is twisted once in either a clockwise or counterclockwise manner, followed by a new twofold twisting in the opposite direction. Alternatively, "homochiral" twisting leads to another chiral arrangement with $D_{3}$-symmetry. ${ }^{2,3}$ Thus, the three-fold twisting of a macrocycle could be an attractive methodology for the design of multiple dynamic chiral structures. ${ }^{4,5}$ Indeed, one successful example has already been reported, i.e., a twisted macrocycle that achieved dynamic interconversion between two dynamic chiral forms with $C_{2}$ or $D_{3}$-symmetry, ${ }^{5 a}$ while there have been many examples of robust macrocycles with $D_{3}$-symmetry based on undynamic chiral spacing units. ${ }^{5 b-k, 6}$

We were interested in two points. First, we wished to construct

\footnotetext{
a. Department of Chemistry, Faculty of Science, Hokkaido University, Sapporo 0600810, Japan. Fax: +81 11 706-2714; Tel: +81 11 706-3396; E-mail: katoono@sci.hokudai.ac.jp.

Electronic Supplementary Information (ESI) available: [details of NMR, UV and CD spectroscopic data (Fig. S1-S6), experimental details of new compound synthesis (Scheme S1), and copies of ${ }^{1} \mathrm{H}$ and ${ }^{13} \mathrm{C}$ NMR spectra]. See DOI: 10.1039/x0xx00000x
}

I

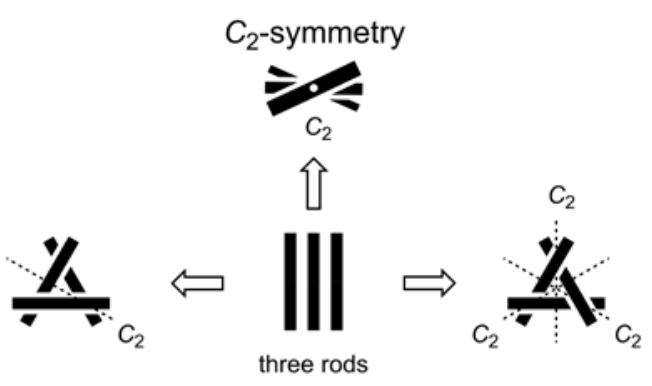

$\mathrm{C}_{2}$-symmetry

$D_{3}$-symmetry

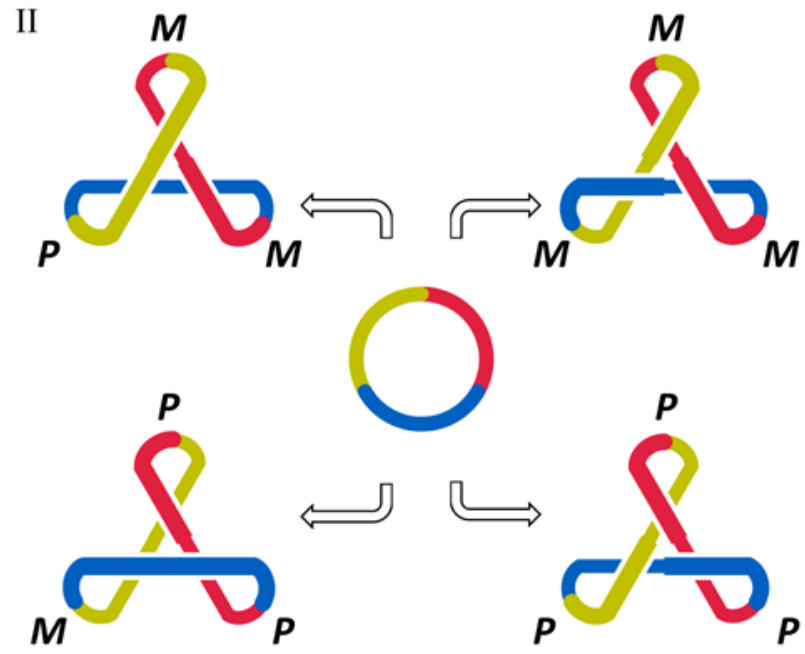

Scheme 1 Chirality generated (I) in assemblies of three achiral rods, and (II) in a macrocycle through three-fold twisting.

a dynamic system where a macrocyclic molecule can adopt dynamic chiral forms with both $C_{2}$ - and $D_{3}$-symmetry, which can dynamically interconvert into each other. ${ }^{5 a}$ Second, we wanted to induce a helical-sense preference in each enantiomeric pair of dynamic chiral forms ( $M M P$ and $P P M$ for a $C_{2}$-symmetric form, and $M M M$ and $P P P$ for a $D_{3}$-symmetric form).

Thus, we designed and synthesized macrocycles $(R)_{6}-\mathbf{1 a}$ and $\mathbf{1 b}$ (Fig. 1 and Scheme S1). Three achiral rods of 1,4- 

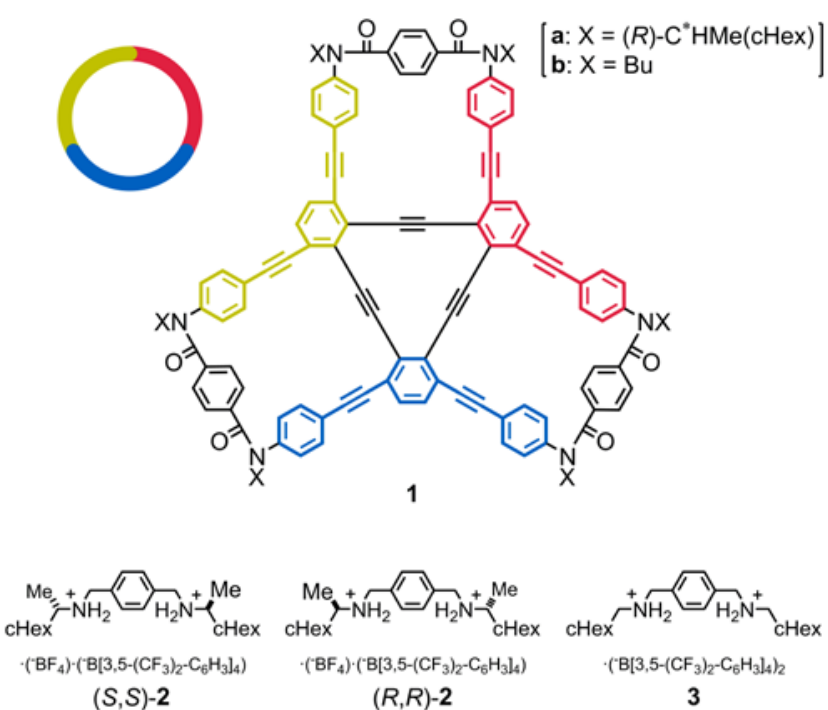

Local dynamic helicity:

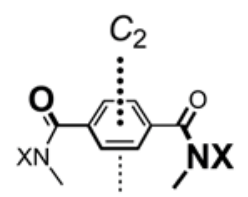

M-helicity

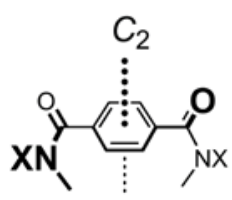

$P$-helicity
Fig. 1 Chemical structures of $(R)_{6}-\mathbf{1} \mathbf{a}$ and $\mathbf{1} \mathbf{b}$, and ditopic guests ${ }^{8}(S, S)-\mathbf{2},(R, R)-\mathbf{2}$ and $\mathbf{3}$.

bis(phenylethynyl)benzene were used to form cyclic assemblies, where each rod is covalently linked to the other rods through triple bonds for maintenance of the framework. ${ }^{7}$ Each terminal of the rods is bridged by a three-fold terephthalamide unit, ${ }^{8}$ which can adopt dynamic chiral forms with $M$ - or $P$-helicity by twisting of the two amide groups with respect to the central benzene ring (Fig.1). Through three-fold twisting of the local dynamic chiral unit, we envisioned two global chiral forms with $C_{2}$-symmetry ( $M M P$ and $P P M$ ) or $D_{3}$-symmetry ( $M M M$ and $P P P$ ) (Scheme 1-II), which would be interconvertible through inversion between local dynamic chiral forms. The helical-sense preferences would arise as a result of a transmission of chirality from a chiral auxiliary $[(R)$-group in 1a] or from an external chiral source $[(S, S)-2$ or $(R, R)-2]$ to the local dynamic chiral units.

A conformational search for a model macrocycle $\mathbf{1}^{\prime}[\mathrm{X}=\mathrm{Me}]$ showed that three achiral rods were assembled to adopt both global chiral forms with $C_{2}$ - and $D_{3}$-symmetry (Fig.2).

The dynamic structures of $\mathbf{1 b}$ in solution were first investigated by ${ }^{1} \mathrm{H}$ NMR spectroscopy. At room temperature, only a single set of averaged resonances were observed, which implied the presence of a single species with apparent " $D_{3 \mathrm{~h}}{ }^{4 \mathrm{~b}}$ symmetry (Fig.S1). At lower temperatures (<233 K), an averaged signal for two methylene protons became an anisochronous pair, which showed that these protons were located adjacent to some chiral environment and in a diastereomeric relationship with each other $\left(\mathrm{H}^{\mathrm{E}^{\prime}}\right.$ and $\left.\mathrm{H}^{\mathrm{E}^{\prime \prime}}\right) \cdot{ }^{9}$ Each of these two signals ultimately split into three signals below $213 \mathrm{~K}$, which revealed the presence of a $C_{2}$-symmetric species. Over the entire range of temperatures, there was little difference in the chemical shift

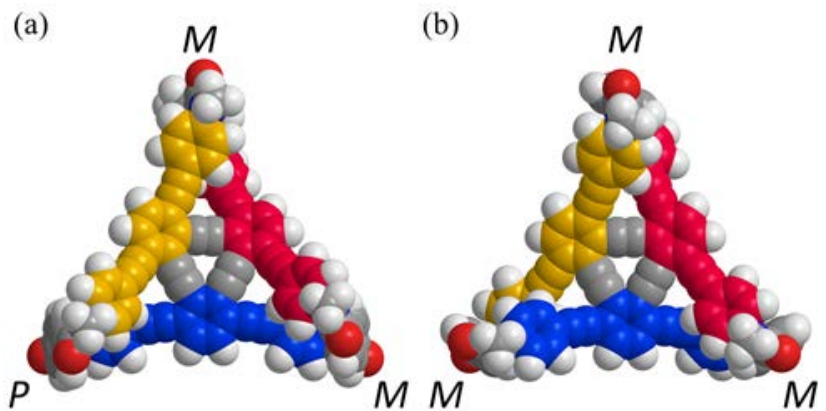

Fig. 2 Energy-minimized structures of model macrocycle $\mathbf{1}^{\prime}$ [ $\mathrm{X}=\mathrm{Me}$ ] with (a) $C_{2}$-symmetry (rel. $0 \mathrm{~kJ} \mathrm{~mol}^{-1}$ ) and (b) $D_{3}$-symmetry $\left(+0.80 \mathrm{~kJ} \mathrm{~mol}^{-1}\right)$, obtained by a conformational search using MacroModel software (v11.8 OPLS3e, Monte Carlo Multiple Minimum method, non-solvated, 20,000 steps). Only one of two enantiomeric conformations is depicted.

for every proton of $\mathbf{1 b}$. This result showed that a single species was dominantly present in equilibrium (Fig.S2b).

The results of VT-1 H NMR measurements for $(R)_{6}-1$ a could be similarly interpreted (Fig.S2a), although dynamic chiral forms with $M$ - or $P$-helicity were no longer enantiomers due to the internal chirality $(R)$. As a consequence, the chemical shift values for $\mathrm{H}^{\mathrm{D} \alpha}$ and $\mathrm{H}^{\mathrm{D} \beta}$ and their populations were different. This imbalance was considered to be the result of the intramolecular transmission of chirality $(R)$ to dynamic chiral forms.

Next, we examined the complexation of $\mathbf{1 b}$ with a hydrogenbonding guest to confirm whether or not another chiral form with $D_{3}$-symmetry could be induced. The ${ }^{1} \mathrm{H}$ NMR spectra of $\mathbf{1} \mathbf{b}$ in the presence of a ditopic guest $(R, R)-\mathbf{2}$ are shown in Fig.3. Upon mixing, there were significant upfield-shifts induced for both the central phenylene protons $\left(\mathrm{H}^{\mathrm{C}}\right)$ in $\mathbf{1} \mathbf{b}$ and the central phenylene protons $\left(\mathrm{H}^{\mathrm{a}}\right)$ in $\mathbf{2}$. These changes in the chemical shift showed that the ditopic guest was captured at the two amide carbonyls of a terephthalamide unit. Also, we observed complexation-induced shifts for other protons, especially for $\mathrm{H}^{\mathrm{A}}$ that was furthest from the binding site. Based on this change $\left(\mathrm{H}^{\mathrm{A}}\right)$, we considered that the dominant form in the dynamic equilibrium changed from $C_{2^{-}}$to $D_{3}$-symmetry upon complexation. ${ }^{10,11}$

Next, we monitored the complexation of $\mathbf{1 b}$ with chiral ditopic guests $(S, S)-\mathbf{2}$ and $(R, R)-\mathbf{2}$ by CD spectroscopy (Fig.4). Mirrored Cotton effects were induced in the absorption region of $\mathbf{1 b}^{13}$ by the addition of each enantiomeric guest. Since there is no reason for the induction of any helical-sense preference by $\mathbf{1} \mathbf{b}$ itself, these induced Cotton effects were attributed to an imbalance in the equilibrium between two chiral forms with $M M M$ and $P P P$ in a complexed state through the supramolecular transmission of external chirality in $\mathbf{2}$.

Finally, we demonstrate the transmission of chirality to dynamic chiral forms of 1 a by CD spectroscopy. As shown by VT-1 H NMR measurements, 1a was present as an invertible diastereomeric pair with $C_{2}$-symmetry, and a particular helical sense was preferred. Based on this finding, induced Cotton effects for $(R)_{6}$ 1a itself were considered to be the result of intramolecular transmission of internal chirality $(R)$ to dynamic chiral forms with $M M P$ and PPM (Fig.5, broken line). Through the complexation of $(R)_{6}-1$ a with an achiral ditopic guest 3 , which 


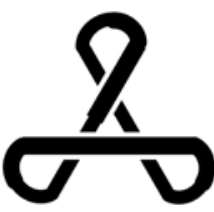

$\mathrm{C}_{2}$

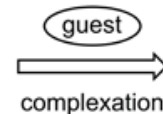

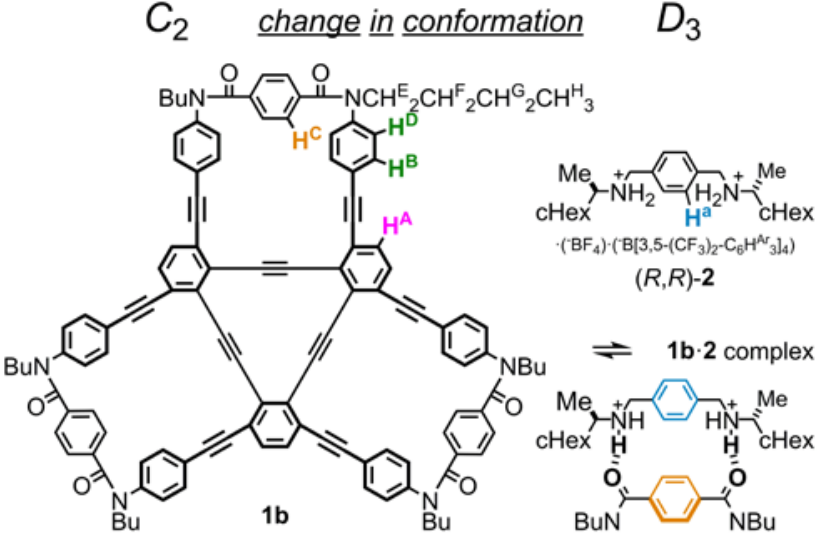

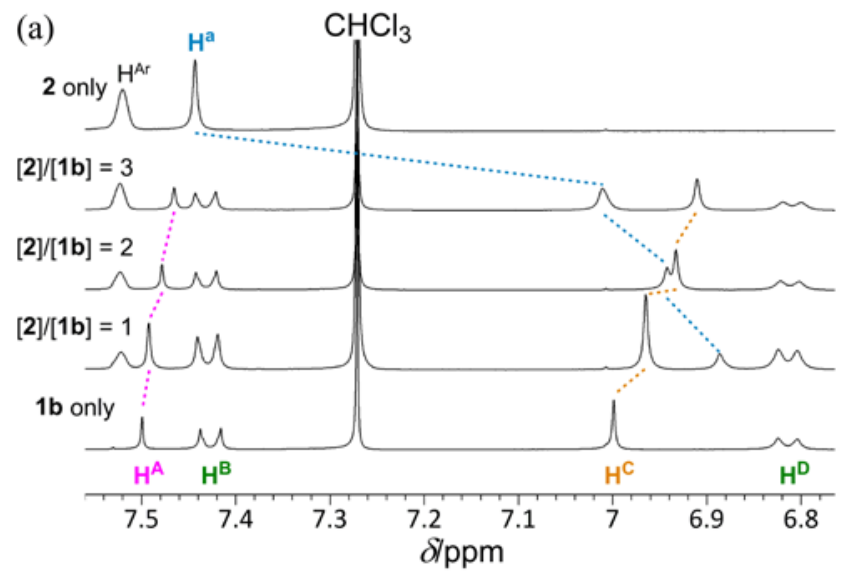

(b)

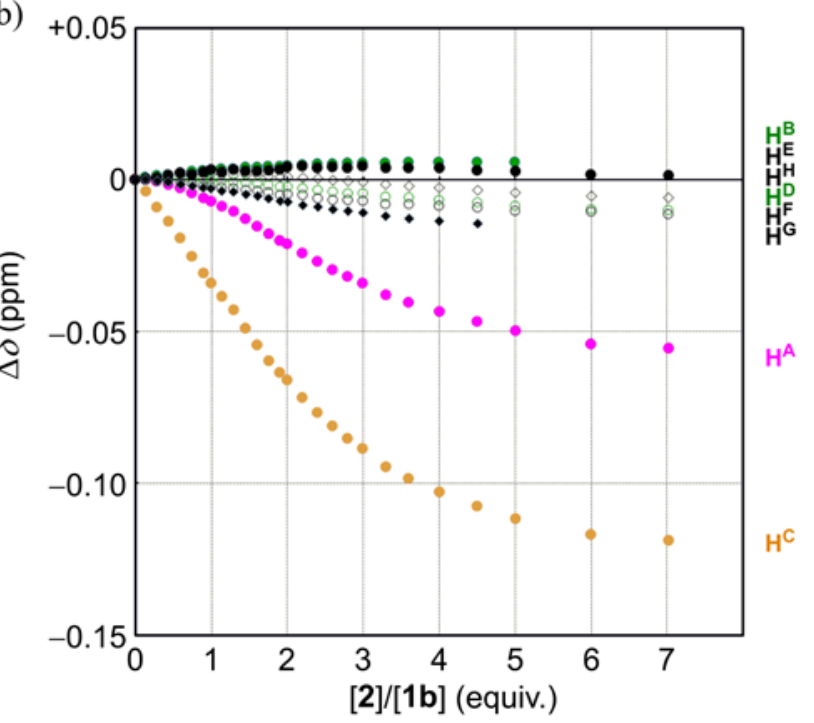

Fig. 3 (a) Partial ${ }^{1} \mathrm{H}$ NMR spectra (aromatic region) of $\mathbf{1 b}(0.7 \mathrm{mM})$ in the presence of $(R, R)$-2 [0 (1b only), 1,2 and 3 equiv.), and $(R, R)$-2. All spectra were measured in $1.7 \mathrm{vol} \%$ acetonitrile- $d_{3} /$ chloroform- $d$ at $303 \mathrm{~K}$; (b) titration curves based on changes in the chemical shifts $\left(\Delta \delta=\delta_{1 \mathbf{b} \cdot \mathbf{2}}-\delta_{1 \mathrm{~b}}\right)$ for protons $\mathrm{H}^{\mathrm{A}}-\mathrm{H}^{\mathrm{H}}$ of $\mathbf{1 b}$.

had no preference for a particular helical sense, the original Cotton effects were changed (Fig.5, solid lines). ${ }^{14}$ This result 1b

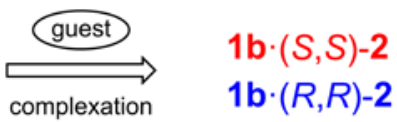

$C_{2}$ change in $\underline{\text { conformation }} \quad D_{3}$

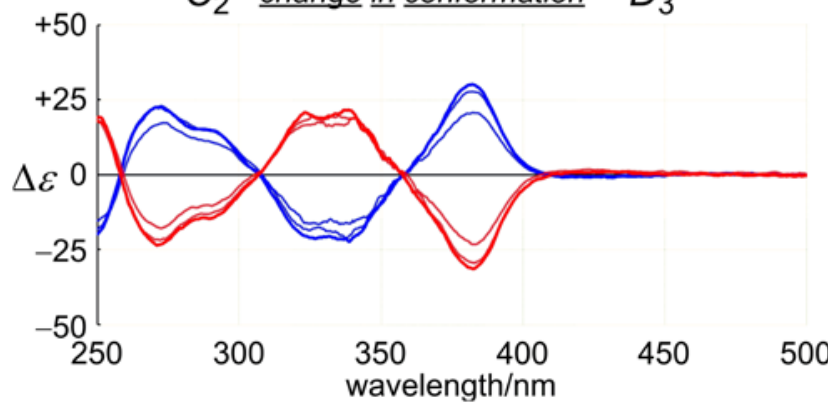

Fig. $4 \mathrm{CD}$ spectra of $\mathbf{1 b}\left(8.7 \times 10^{-5} \mathrm{M}\right)$ in the presence of chiral guests $(R, R)-\mathbf{2}$ (blue lines; $3,4,6$ and 9 equiv.) or (S,S)-2 (red lines; 3, 4, 6 and 9 equiv.), measured in dichloromethane at $293 \mathrm{~K}$.

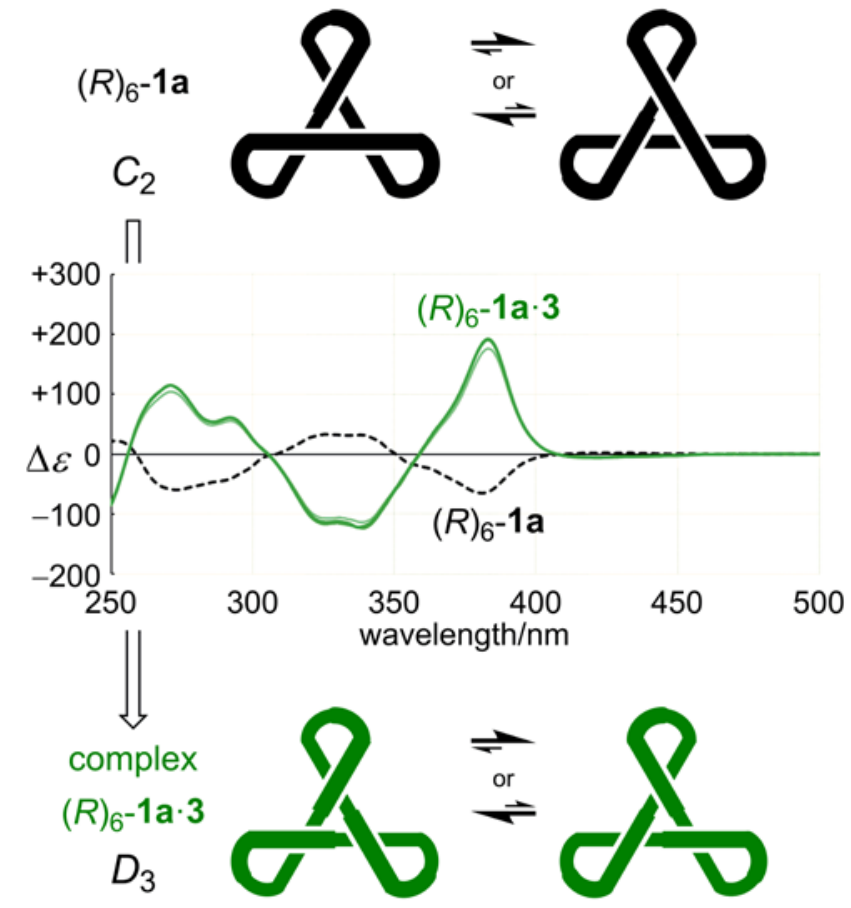

Fig. $5 \mathrm{CD}$ spectra of $(R)_{6}-\mathbf{1 a}\left(7.8 \times 10^{-5} \mathrm{M}\right)$ in the absence (black broken line; $(R)_{6}-1 \mathbf{a}$ only) and presence of 3 (green lines; 3, 4, 6 and 9 equiv.). All spectra were measured in dichloromethane at $293 \mathrm{~K}$.

indicated that a conformational change was induced to adopt another chiral form with $D_{3}$-symmetry in a complexed state, and that a particular sense of $M M M$ or PPP was preferred through the intramolecular transmission of internal chirality $(R)$. Similar changes in absorption and Cotton effects were induced when chiral ditopic guests were added (Fig.S5). These results indicated that either of the chiral guests could lead to a change in the global conformation upon complexation, and that the supramolecular transmission from $(S, S)$-2 was completely invalid, while it seemed that $(R, R)-\mathbf{2}$ could cooperatively assist the dominant intramolecular transmission of internal chirality $(R)$ in a complexed state. 
VT-CD measurements for $(R)_{6}-\mathbf{1 a}$ itself and $\mathbf{1} \mathbf{b}$ in the presence of a chiral guest showed that the shapes of induced Cotton effects were maintained, respectively, while the intensities were attenuated or enhanced with several isochoric points with an increase or decrease in temperature (Fig.S6). These results indicated that the two different chiral forms of 1 with $C_{2}$ - and $D_{3}$-symmetry were dynamic, respectively. Since the induced Cotton effects for a complex of $\mathbf{1 b} \cdot \mathbf{2}$ (Fig.4) were apparently similar to those for a complex of $(R)_{6}-\mathbf{1 a} \cdot \mathbf{3}$ (Fig.5), either of 1a and $\mathbf{1 b}$ could be considered to adopt $D_{3}$-symmetric forms in a complexed state.

In conclusion, we have demonstrated that two dynamic chiral structures with $C_{2^{-}}$or $D_{3}$-symmetry were generated based on assemblies of three achiral rods in a macrocycle. A conformational transition between these two chiral structures was achieved through complexation with a hydrogen-bonding guest. In both uncomplexed and complexed states, the intramolecular transmission of chirality associated with a macrocycle $\left[(R)_{6}-1 \mathbf{a}\right]$ was valid to induce the helical-sense preference for a particular enantiomeric form of MMP or PPM ( $C_{2}$-symmetry) and MMM or PPP ( $D_{3}$-symmetry).

\section{Conflicts of interest}

There are no conflicts to declare.

\section{Notes and references}

1 P. Jonkheijm, P. van der Schoot, A. P. H. J. Schenning, E. W. Meijer, Science, 2006, 313, 80; H. Engelkamp, S. Middelbeek and R. J. M. Nolte, Science, 1999, 284, 785; K. Sakajiri, T. Sugisaki, K. Moriya and S. Kutsumizu, Org. Biomol. Chem., 2009, 7, 3757; Y. Zhong, Y. Yang, Y. Shen, W. Xu, Q. Wang, A. L. Connor, X. Zhou, L. He, X. C. Zeng, Z. Shao, Z. Lu and B. Gong, J. Am. Chem. Soc., 2017, 139, 15950; H. Yamagishi, T. Fukino, D. Hashizume, T. Mori, Y. Inoue, T. Hikima, M. Takata and T. Aida, J. Am. Chem. Soc., 2015, 137, 7628.

2 Bridging at different terminals of two rods leads to a macrocycle with another type of chirality, known as a trefoil knot. ${ }^{3}$ K. I. Arias, E. Zysman-Colman, J. C. Loren, A. Linden and J. S. Siegel, Chem. Commun., 2011, 47, 9588.

3 S. D. P. Fielden, D. A. Leigh and S. L. Woltering, Angew. Chem. Int. Ed., 2017, 56, 11166.

4 (a) M. Rickhaus, M. Mayor and M. Juríček, Chem. Soc. Rev., 2016, 45, 1542; (b) L. Barnett, D. M. Ho, K. K. Baldridge and R. A. Pascal Jr., J. Am. Chem. Soc., 1999, 121, 727; (c) S. Nobusue, Y. Mukai, Y. Fukumoto, R. Umeda, K. Tahara, M. Sonoda and Y. Tobe, Chem. Eur. J., 2012, 18, 12814.

5 (a) Z. J. Kinney and C. S. Hartley, J. Am. Chem. Soc., 2017, 139, 4821; (b) E. P. Kyba, G. W. Gokel, F. de Jong, K. Koga, L. R. Sousa, M. G. Siegel, L. Kaplan, G. D. Y. Sogah and D. J. Cram, J. Org. Chem., 1977, 42, 4173; (c) S. Anderson, U. Neidlein, V. Gramlich and F. Diederich, Angew. Chem. Int. Ed. Engl., 1995, 34, 1596; (d) L. P. Olson, J. Mol. Struct: THEOCHEM, 2004, 680, 65; (e) T. Fukino, N. Fujita and T. Aida, Org. Lett., 2010, 12, 3074; (f) G. R. Schaller, F. Topić, K. Rissanen, Y. Okamoto, J. Shen and R. Herges, Nat. Chem., 2014, 6, 608; (g) Y. Morisaki, K. Inoshita and Y. Chujo, Chem. Eur. J., 2014, 20, 8386; (h) K. Takaishi, T. Yabe, M. Uchiyama and A. Yokoyama, Tetrahedron, 2014, 70, 730; (i) F. Sannicolò, P. R. Mussini, T. Benincori, R. Cirilli, S. Abbate, S. Arnaboldi, S. Casolo, E. Castiglioni, G. Longhi, R. Martinazzo,
M. Panigati, M. Pappini, E. Q. Procopio and S. Rizzo, Chem Eur. J., 2014, 20, 15298; (j) N. Saito, R. Terakawa and M. Yamaguchi, Chem. Eur. J., 2014, 20, 5601; (k) G. Naulet, L. Sturm, A. Robert, P. Dechambenoit, F. Röhricht, R. Herges, H. Bock and F. Durola, Chem. Sci., 2018, 9, 8930.

6 J. M. Fox and D. Lin, J. Org. Chem., 1998, 63, 2031; W. Nakanishi, T. Matsuno, J. Ichikawa and H. Isobe, Angew. Chem. Int. Ed., 2011, 50, 6048; Z. He, E. Wang, J. W. Y. Lam, Y. Li, Z. Lin and B. Z. Tang, ChemPlusChem, 2015, 80, 1245; B. Köhler, V. Enkelmann, M. Oda, S. Pieraccini, G. P. Spada and U. Scherf, Chem. Eur. J., 2001, 7, 3000; A. Robert, P. Dechambenoit, E. A. Hillard, H. Bock and F. Durola, Chem. Commun., 2017, 53, 11540; Z.-B. Li, J. Lin and L. Pu, Angew. Chem. Int. Ed., 2005, 44, 1690.

7 C. Eickmeier, H. Junga, A. J. Matzger, F. Scherhag, M. Shim and K. P. C. Vollhardt, Angew. Chem. Int. Ed. Engl., 1997, 36, 2103.

8 (a) R. Katoono, K. Kusaka, Y. Tanaka, K. Fujiwara and T. Suzuki, Org. Biomol. Chem., 2018, 16, 1167; (b) R. Katoono, Y. Tanaka, K. Fujiwara and T. Suzuki, J. Org. Chem., 2014, 79, 10218.

9 The barrier to the dynamic interconversion between two local enantiomeric forms with $M$ - or $P$-helicity was estimated by the observation of the coalescence of methylene protons $\mathrm{H}^{\mathrm{E}}$ and $\mathrm{H}^{\mathrm{E}}\left(\Delta v=175 \mathrm{~Hz}, T_{\mathrm{c}}=229 \mathrm{~K}, \Delta G^{\ddagger}=44 \mathrm{~kJ} \mathrm{~mol}^{-1}\right)$.

10 Based on changes in the chemical shift $\left(\mathrm{H}^{\mathrm{B}}-\mathrm{H}^{\mathrm{H}}\right)$ induced by the proximity of a guest, Job plots were created to show that a 1:2 complex was predominantly present, ${ }^{11,12}$ and that the binding constants were estimated by a curve-fitting method to be $K_{1}=5 \times 10^{2} \mathrm{M}^{-1}$ and $K_{2}=3 \times 10^{3} \mathrm{M}^{-1}$ (Fig.S3A). This moderate positive allosterism would support the change in conformation induced before and after complexation. For comparison, a control experiment was examined with a single-ring model $\mathbf{4}^{8 \mathrm{~b}}$ (Fig.S3b).

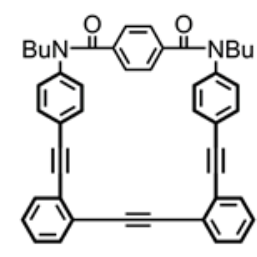

4

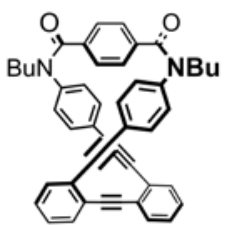

M

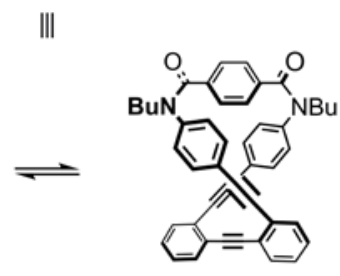

$\boldsymbol{P}$
11 We found some maximum values of $\Delta \Delta \varepsilon \cdot \chi_{1}$ a between molar fractions of 0.25-0.33 in a Job plot based on changes in molar CDs (Fig.S5B). This result may indicate a composite stoichiometry of $1: 2$ and $1: 3$ complexation. ${ }^{12}$ For such higher-ordered complexation $(1: n)$ of a homotopic host, there would be some limitation to the determination of the stoichiometry based on molar CDs due to difficulties in assuming helical-sense preferences induced for each complex.

12 F. Ulatowski, K. Dąbrowa, T. Bałakier and J. Jurczak, J. Org. Chem., 2016, 81, 1746.

13 Also, there was a change in absorption of $\mathbf{1 b}$ upon mixing (Fig.S4).

14 Also, there was a change in absorption of 1a upon mixing (Fig.S5A). 